of Conn.; and various places in Mass., including Winchendon, Greylock Mt., Penikese, Cuttyhunk, and Martha's Vineyard Ids. The specimens from Greylock Mt. consist of both long and short winged adults and young, showing that the species undoubtedly breeds there; those from Speckled Mt. on the contrary are all long-winged adults and probably flew there, having been observed by $\mathrm{Mr}$. Scudder in the middle of Sebago Lake almost simultaneously. A notation and description by $\mathrm{Mr}$. Scudder of its song and attitude during stridulation will be found in Distribution of Insects in New Hampshire and the 23rd report of the Entomological Society of Ontario.

\title{
A THYSANURAN OF THE GENUS ANOURA.
}

BY F. L. HARVEY, ORONO, ME.

Prof. A. S. Packard in his "Syn. Thys. of Essex Co. Mass." p. 27 describes a species of Anoura under the name $A$. gibbosa, which was collected at Brunswick, Me. The description is so meagre and differs so materially from a form found in similar situations about Orono, Me., that we submit the following account of specimens examined.

Description.- Lead colored or pale indigo bluish. Body short and broad with broad segment. Head long in proportion to the other segments, and divided above into two areas: a wide anterior flattened portion, bearing three rounded tubercles. The middle one much larger and marked by about twenty small irregular color patches. The posterior portion narrower, ridged, bearing five tubercles, the middle one rectangular larger and two lobed by a transverse depression. The others small and rounded.

The prothorax bears four tubercles, the two median ones small or obsolete, the location indicated by hairs. The segments from the third to the eighth inclusive six-tuberculate. Ninth segment four tuberculate.
The body ending in two large tubercles. The tubercles armed with whitish hairs at the apex which become larger, longer and more numerous toward the posterior part of the body. The tubercles are colored like the body but surrounded at the base by a light colored ring which has light colored lines radiating from it to the apex of the tubercles breaking the color into six sub-triangular zones. The tubercles on the second segment are triangular at the base and the color broken by lighter lines into twelve irregular patches nine surrounding three. Body widest at 7 th to 8 th segments. The bucal cone acute, broad at the base, prominent and projecting beyond the head, as shown in Fig. 2. Antennae short, stout, hirsute, as long as half the width of the head. Basal joint broadest. Three basal joints about equal. Terminal joint longest, narrowest, conical, lighter colored.

Legs short and stout slightly longer than half width of body. Underside of body yellowish at the insertion of the legs.

Measurements.-Total $\mathrm{I} .9 \mathrm{~mm}$. to $\mathrm{I} .6 \mathrm{~mm}$. Greatest width .798 at 8 th seg., head, .399 $\mathrm{mm}$. long. Breadth $.532 \mathrm{~mm}$. behind but at base of antennae $.319 \mathrm{~mm}$. Antennae.2 $3 \mathrm{~mm}$. 
Habitat. Common about Orono, Me., in decaying wood or under boards, stones, logs, etc., at all seasons.

Remarks. The illustrations were drawn by Mr. Emerton from live specimens furnished by the writer. Fig. I shows a full grown specimen somewhat too broad from pressure. Fig. 2 ventral view of some specimen. Fig. 3 represents a form found with the other our specimens as the six tubercles are plainly on the tergal region and in plain view when the specimen is walking. We would suggest the name Anoura 6-tuberculata n. sp. should the form prove distinct from Packard's species when compared with his type. Our form when disturbed or killed in alcohol or balsam puts the antennae at right angles to the body as shown in

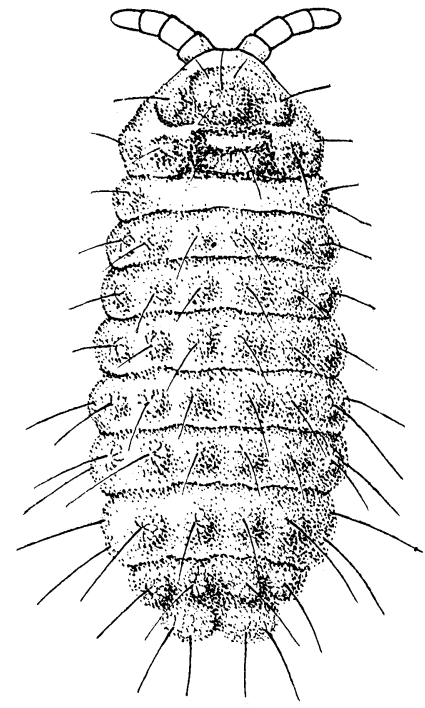

Fig. 1 .

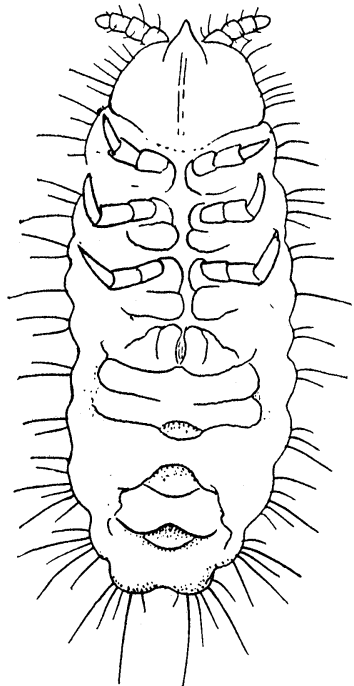

Fig. 2.

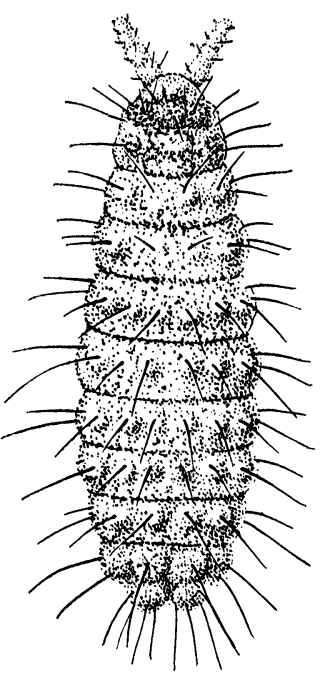

Fig. 3. and may be the same species though smaller and the body much more slender and the antennae narrower.

Our specimens are larger than Packard's, and the tubercles on the head different and the number of tubercles on the segments greater. Packard's statement "four large subacute tuber. cles across the upper side of each segment" certainly does not apply to
Lubbock's figure of $A$. muscorum Temp. Mr. Macgillivray has proposed the name Aphoromma for Anoura which is preoccupied. Should this prove to be the same as Packard's species the more minute description and the figures will be interesting. We do not know that Packard's species has been figured. 

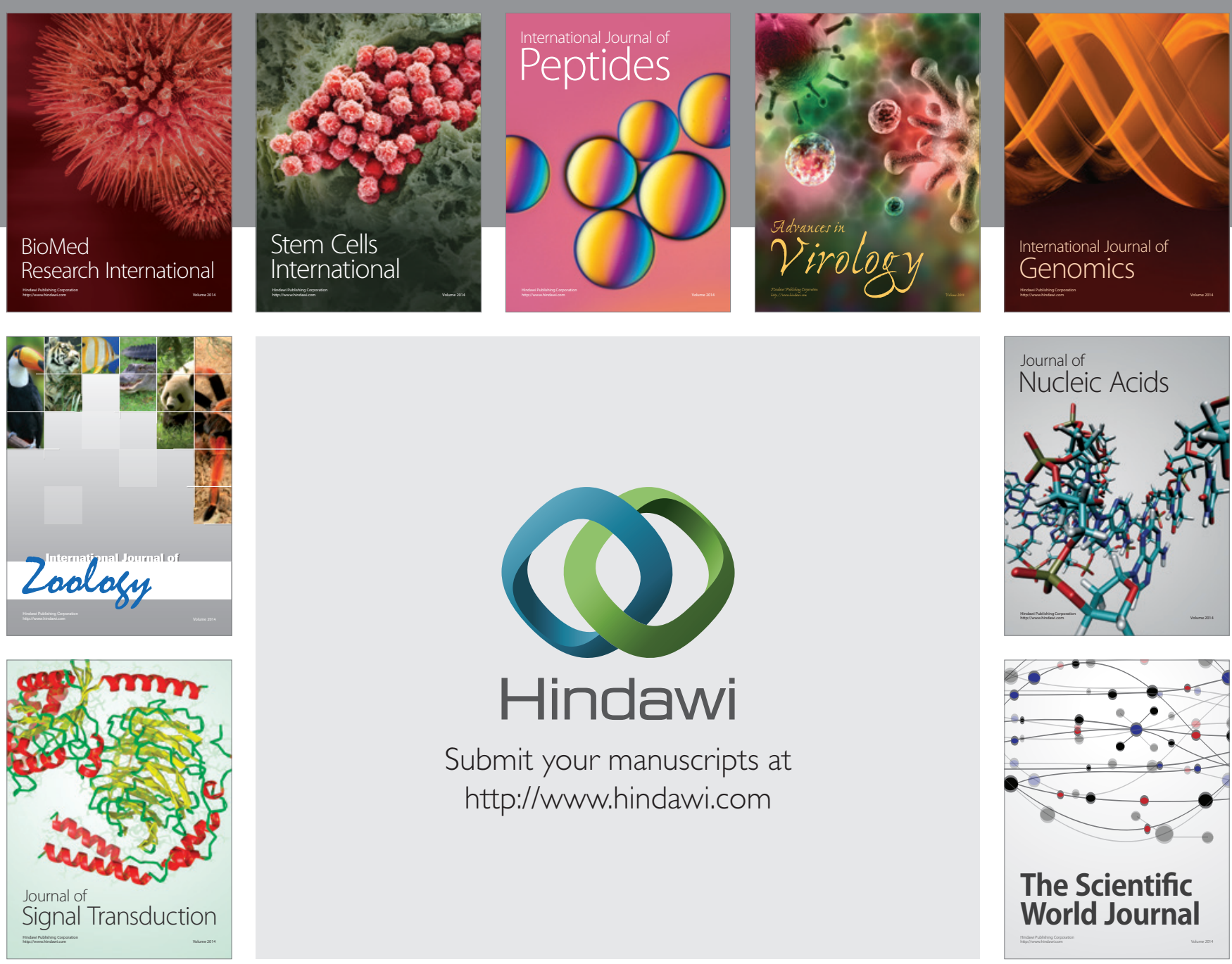

Submit your manuscripts at

http://www.hindawi.com
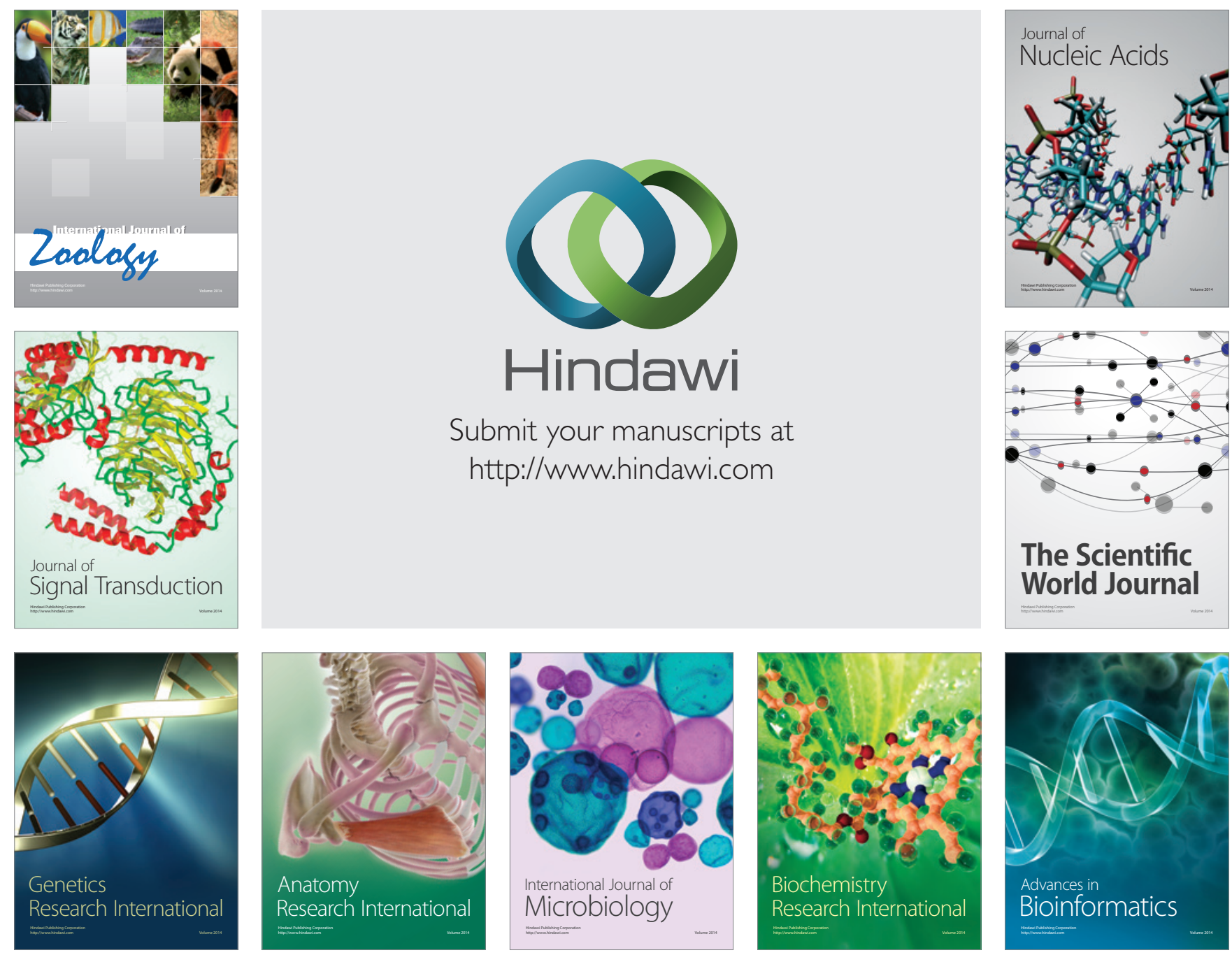

The Scientific World Journal
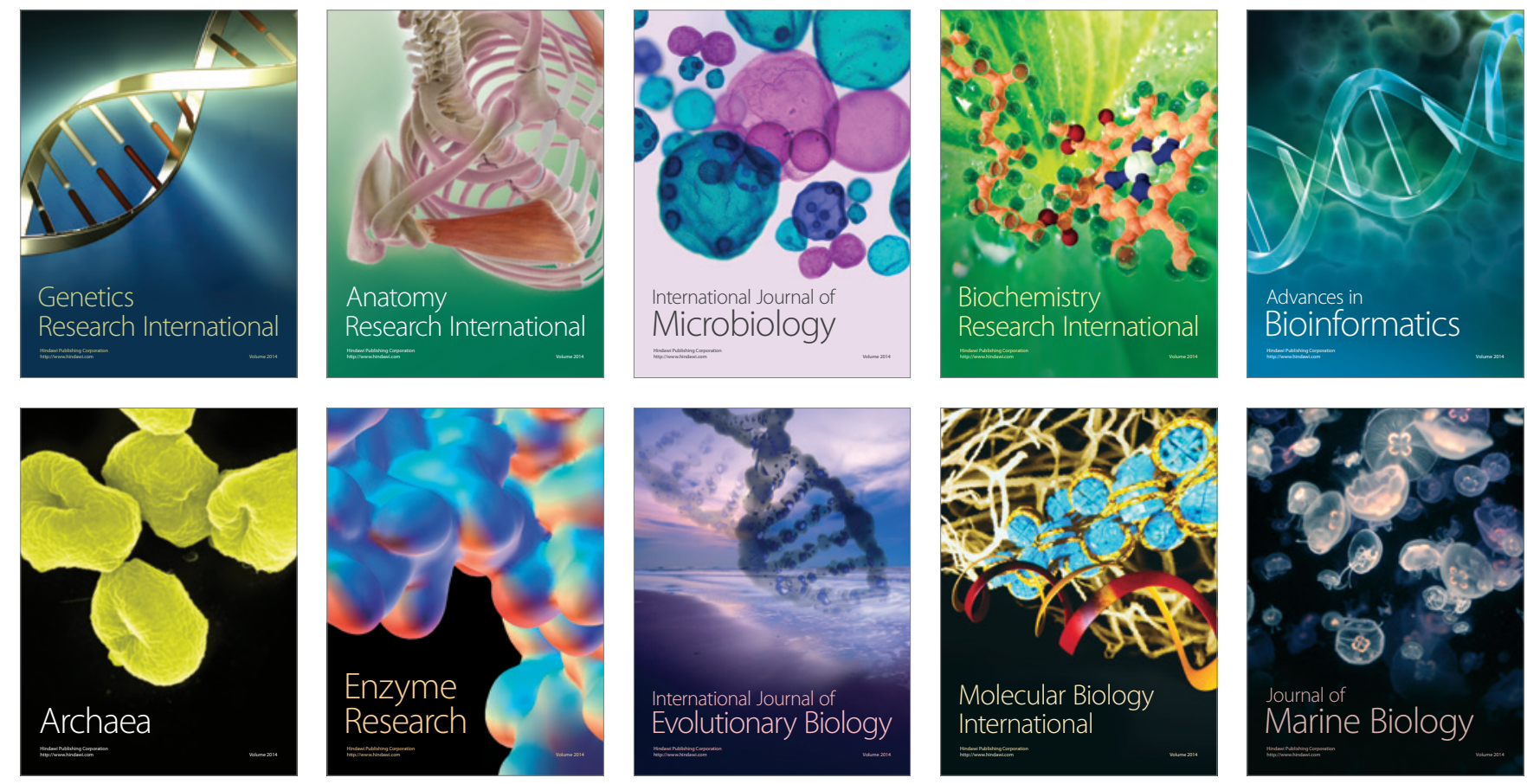